The average pregnancy length was 36.36 weeks and the mean birthweight was 2878.90 grams.2 growth restriction was identified and several atopic dermatitis, no teratogenic effect.

13 patients never had a new flare postpartum and in the others the mean time of postpartum flare was 12.1 weeks

Conclusions: Patients with RA can have successful pregnancies. More than $60 \%$ of pregnancies have been planned. Pregnancy decreases disease activity, but many deliveries are followed by RA flares. No fetal abnormalities were diagnosed. References:

[1] Østensen $M$, et all. State of the art: Reproduction and pregnancy in rheumatic diseases: Autoimmun Rev. 2015 May;14(5):376-86. doi: 10.1016/ j.autrev.2014.12.011. Epub 2014 Dec 30.

Disclosure of Interest: None declared

DOI: 10.1136/annrheumdis-2017-eular.6605

\section{AB0295 THE RECALL SURVEY: DATA FROM A MULTICENTER EDUCATIONAL EVENT ON PATIENTS WITH RA}

A. Delle Sedie ${ }^{1}$, E. Filippucci ${ }^{2}$, O. Epis ${ }^{3}$, P. Macchioni ${ }^{4}$, S. Tropea ${ }^{5}$, C. Bonali ${ }^{6}$ M. Canzoni ${ }^{7}$, A. lagnocco ${ }^{8} .{ }^{1}$ Rheumatology Unit, University of Pisa, PISA;

${ }^{2}$ Rheumatology Department, Università Politecnica delle Marche, Jesi;

${ }^{3}$ Rheumatology Unit, Ospedale Niguarda Milano, Milano; ${ }^{4}$ Rheumatology Unit, Reggio Emilia Hospital, Reggio Emilia; ${ }^{5} 5$ ASP7 Busacca Hospital, Ragusa;

${ }^{6}$ Rheumatology Unit, Ospedale San Paolo, Bari; ${ }^{7}$ Local Health Unit (ASL) Rome 1, Rome; ${ }^{8}$ Academic Rheumatology Unit, Università degli Studi di Torino, Torino, Italy

Background: Ultrasound (US) is able to show subclinical synovitis in patients (pts) with rheumatoid arthritis (RA) who are in clinical remission (CR); this has been proposed as a predictive factor for both clinical flares and progression of the structural damage in CR pts.

Objectives: To investigate the US characteristics of RA pts presenting either CR or low disease activity (LDA)

Methods: In 2015 an educational event focused on the added value of US in RA pts was held in 22 rheumatology centers in Italy. After a brief presentation on the evidence of US added value for the clinician given by expert sonographers (rheumatologists with a special interest in US that were performing US as their usual activity for many years), in every center, the local rheumatologists provided RA pts to be examined by US. All the US machines were identical both for type (Logiq E R7, General Electrics, with a 4.2-13 MHz linear probe) and settings (both for grey-scale and power Doppler (PD)). Pts signed an informed consent and a brief history of them was collected by the local rheumatologists (previous and current therapy, DAS28, HAQ score). The US examination was performed bilaterally on wrists, MCP and MTP joints, looking for synovitis (effusion, synovial proliferation and PD signal) and bone erosions. The positive findings were scored according to a 0-3 score for synovitis components and presence/absence for erosions; the number and size of the largest erosion was also registered.

Results: Demographic and descriptive data of the 433 pts examined are reported in Table I. Pts were divided on the basis of the DAS28 result. Statistically significant differences in age and disease duration were registered between the group in CR and the group with DAS28 $\geq 3.2(p=0,019$ and $p=0,012$, respectively), while no differences were found for HAQ or MTX use. Higher positivity of findings, regardless which was the score, was present in LDA group for effusion, synovial proliferation and PD signal. Significant differences were seen between $C R$ and LDA group for effusion (general, MCP and MTP joints; $p=0,011, p=0,026, p=0,017$ and $p=0,013$, respectively), PD positivity (general, wrist, MCP and MTP joints; $p=0,006, p=0,023$ and $p=0,05$, respectively) and erosions $(p=0,002)$, with higher positivity for pts in LDA.

Table 1. demographic data

\begin{tabular}{lccc}
\hline & DAS28 $<2.6$ & DAS28 2.6-3.2 & DAS28 $\geq 3.2$ \\
\hline $\mathrm{N}(\mathrm{M}: \mathrm{F})$ & $155(34: 121)$ & $170(39: 131)$ & $108(20: 88)$ \\
Age (mean $\pm S D ; y y)$ & $56.1 \pm 14.3$ & $59.2 \pm 12.2$ & $60.5 \pm 11.4$ \\
Disease duration (mean $\pm S D ;$ dd) & $2368.49 \pm 2565.39$ & $3274.16 \pm 2948.36$ & $1966.53 \pm 1884.58$ \\
\hline
\end{tabular}

Conclusions: The US assessment in this large cohort of RA pts showed frequent positive findings both in the CR and in the LDA group, confirming the results from previous studies. US is a useful imaging tool for the detection of subclinical joint abnormalities in RA.

Disclosure of Interest: None declared

DOI: 10.1136/annrheumdis-2017-eular.4475

\section{AB0296 HMG-COA REDUCTASE INHIBITOR DRUGS (STATINS) BENEFIT IN CARDIOVASCULAR RISK PREVENTION AND AMELIORATE DISEASE ACTIVITY IN PATIENTS WITH RHEUMATOID ARTHRITIS}

A. Hon, M. Sultanova. Cardiorheumatology, Tashkent Medical Academy, Tashkent, Uzbekistan

Background: Patients with active rheumatoid arthritis (RA) are frequently diagnosed with an atherogenic lipid profile and supra-aortic vessel ultrasound signs of atheromatous plaques, which have been linked to the inflammatory activity of RA. Recent experimental and clinical evidences suggest that the beneficial effects of statins are pleiotropic and have been proposed to have anti-inflammatory and immunomodulatory effects, inhibiting proinflammatory cytokines (IL-1 $\beta, 6,8$, TNF- $\alpha$ ), adhesion molecules (sICAM 1, E-, P-selectin), osteoprotegerin, which are implicated in RA pathogenesis. However, the beneficial role of statin therapy in clinical improvement and their benefit-risk profile are still debatable.

Objectives: To evaluate the effect of medium-term rosuvastatin therapy on lipid profile, endothelial dysfunction and RA activity in patients with rheumatoid arthritis (RA) in comparison with conventional disease modifying antirheumatic drugs (DMARD) therapy.

Methods: The study included 82 patients in the Specialized Course Outpatient Therapy Department of the 1st Clinic of Tashkent Medical Academy of age group between 44 and 65 years (mean $52 \pm 8.4$ ), predominantly female gender $(n=57,69.5 \%)$, with early RA (mean disease duration 9.2 \pm 2.4 months), and divided into 2 groups. Group $1(n=40)$ received methotrexate (MTX; 7.5 $\mathrm{mg} /$ week; plus prednisolone (10 $\mathrm{mg} /$ day). Group $2(\mathrm{n}=42)$ received MTX and prednisolone with the same previous doses plus rosuvastatin $(40 \mathrm{mg} /$ day). Lipid profile assessment comprised triglycerides, total cholesterol (TC), high-density lipoprotein cholesterol (HDL-C), low-density lipoprotein cholesterol (LDL-C). Disease activity was assessed by the disease activity score of 28 joints (DAS28), erythrocyte sedimentation rate (ESR), C-reactive protein (CRP) and visual analog scale (VAS). Disease activity, lipid profile and intima-media thickness (IMT) of common carotid arteries were measured before and after 85 days ( 6 months) of treatment.

Results: 4 patients receiving rosuvastatin were excluded due to abnormal liver function test parameters (De Ritis ratio $<0.9$ ), further assessment was thus performed on 78 (Group 2, $n=38$ ) early RA patients. Overall ESR (Group 1: 24.4 \pm 7.26 ; Group 2: $37.4 \pm 12.3$ ) and CRP (Group 1: $5.56 \pm 0.58$; Group 2: $3.71 \pm 1.23$ ) declined significantly during the treatment. The mean DAS28, unconditionally considered as the most important index of clinical disease activity in RA, was found to be lower $(p<0.05)$ in the adjunct statin-treated group (Group 2: $3.68 \pm 0.77$ ) than that of the conventional DMARD treated group (Group 1: $4.45 \pm 1.08)$. Statin significantly reduced LDL-C $(3.9 \pm 1.2 \mathrm{mmol} / \mathrm{l}$ to $3.3 \pm 0.8 \mathrm{mmol} / \mathrm{l}$; $\mathrm{p}=0.08)$ and increased HDL-C $(1.3 \pm 0.6 \mathrm{mmol} / \mathrm{l}$ to $2.0 \pm 0.4 \mathrm{mmol} / \mathrm{l} ; \mathrm{p}=0.06)$ after 6 months of treatment. However, rosuvastatin therapy showed no significant improvement in VAS score $(6.7 \pm 1.5$ to $6.9 \pm 0.6 ; p=0.41)$ and IMT $(1.04 \pm 0.09$ to $1.08 \pm 0.07 ; p=0.05)$.

Conclusions: Statins ameliorate RA activity, reduce potential cardiovascular risk in the context of atherosclerosis and mediate clinically apparent anti-inflammatory effects, but long-term effects and benefit-risk profile should be addressed in the management of elevated risk of cardiovascular events in RA patients.

References:

[1] Husain K., Hernandez W., Ansari R. A., Ferder L. Inflammation, oxidative stress and renin angiotensin system in atherosclerosis. World Journal of Biological Chemistry. 2015;6(3):209-217.

Disclosure of Interest: None declared

DOI: 10.1136/annrheumdis-2017-eular.6577

\section{AB0297 TREATMENT WITH LOW-DOSE PREDNISONE DOES NOT INFLUENCE BODY COMPOSITION DURING THE FIRST YEAR OF RHEUMATOID ARTHRITIS- A PILOT STUDY}

A. Raczkiewicz, O. Bujakowska, A. Juszkiewicz, B. Kisiel, J. Kur-Zalewska M. Tłustochowicz, W. Tłustochowicz. Internal Medicine and Rheumatology, Military Institute of Medicine, Warsaw, Warsaw, Poland

Background: Early change in body composition is one of the risk factors of CVD in rheumatoid arthritis (RA). These changes have been atributed to inflammation and decreased physical activity. Glucocorticosteroids (GCS) reduces inflammation but may influence body composition. There is limited information about the effects of low-dose GCS on body composition in early RA.

Objectives: The aim of the study was to assess the presence of altered body composition in patients with early rheumatoid arthritis (eRA) and to determine whether low-dose prednisone affects body composition.

Methods: 65 consecutive eRA patients (49 women) aged $61 \pm 14$ years were assessed at the time of diagnosis and after 12 months of treatment. All the patients had been treated with methotrexate (target dose $25-30 \mathrm{mg} /$ week) and tapered doses of prednisone (mean dose $4.8 \pm 3.4 \mathrm{mg} /$ day). Disease activity score (DAS28), Health Assesment Questionnaire (HAQ), body mass index (BMI), waist/hip ratio, comorbidities, physical activity and smoking were recorded. Total and regional lean mass and fat mass were measured with dual energy X-ray absorptiometry (DXA). DXA measures were repeated after 12 months in 34 patients ( 24 women) and compared with baseline data.

Results: At baseline fat free mass index (FFMl; $\mathrm{kg} / \mathrm{m}^{2}$ ) was below the 10 th percentile of a reference population in $32 \%$ of the women and $25 \%$ of the men. Reduced FFMI correlated with baseline ESR. Fat mass index (FMI) was above 90 th percentile in $28 \%$ of the women and $42 \%$ of the men. Fat mass index (FMl; $\mathrm{kg} / \mathrm{m}^{2}$ ) correlated with $\mathrm{HAQ}$, age and femoral BMD in women. After 12 months FFMI and FMI did not change significantly. There was no correlation between prednisone doses and the duration of prednisone treatment and changes in regional lean mass and fat mass. The decrase of FFMI (in 16 patients) was associated with higher mean ESR and lower vitamin D3 serum concentration. Conclusions: Low FFMI was common in patients with eRA. The treatment with 
low-dose glucocorticosteroids did not influence altered body composition during the first year of eRA therapy.

References:

[1] Book C, Karlsson MK, Nilsson JA et al. Changes in body composition after 2 years with rheumatoid arthritis. Scandinavian Journal of Rheumatology 2011(40:2); 95-100.

[2] Schtz Y, Kyle UUG, Pichard C. Fat-free mass index and fat mass index percentiles in Caucasians aged 18-98 y. International Journal of Obesity 2002(26);953-960.

[3] Engvall IL, Brisman K, Hafström I et al. Treatment with low-dose prednisolone is associated with altered body composition but no difference in bone mineral density in rheumatoid atrhritis patients: a controlled cross-sectional study. Scandinavian Journal of Rheumatology 2010(40:3)161-168.

Disclosure of Interest: None declared

DOI: 10.1136/annrheumdis-2017-eular.3124

\section{AB0298 ANTIBODIES TO CYCLIC CITRULLINATED PEPTIDE AND MODIFIED CITRULLINATED VIMENTIN: A ROLE IN RHEUMATOID ARTHRITIS ASSOCIATED WITH AUTOIMMUNE THYROIDITIS}

A. Dvorovkin ${ }^{1}$, V. Odin ${ }^{1}$, O. Inamova ${ }^{2}$, V. Tyrenko ${ }^{1}$, M. Toporkov ${ }^{1}$. ${ }^{1}$ Faculty therapy, Military Medical Academy Named After S.M. Kirov; ${ }^{2}$ Clinical Rheumatic Hospital No. 25, St. Petersburg, Russian Federation

Background: Specific antibodies, including antibodies to cyclic citrullinated peptide (ACCP) and modified citrullinated vimentin (AMCV) are markers of severe course of rheumatoid arthritis (RA). At the same time, rheumatoid arthritis often associated with autoimmune thyroiditis (Hashimoto's thyroiditis (HT)).

Objectives: Evaluate the role of antibodies to ACCP and AMCV on the clinical and laboratory features of rheumatoid arthritis in association with autoimmune thyroiditis.

Methods: The study included two groups of patients. The first group of patients included 16 patients ( 14 men and 2 women, mean age $-62.37 \pm 2.12$ years) with $\mathrm{RA}$ in combination with HT and detection in the blood only ACCP (group 1). The second group also included 16 patients (14 women and 2 men, mean age - 52.31 \pm 4.94 years) with RA in combination with HT and detection of ACCP and $A M C V$ in the blood (group 2). In the first group of patients 10 patients had euthyreose, from 5 - hypothyroidism, compensated intake of $L$ - thyroxine, 1 patient - thyrotoxicosis underway medikal euthyreose. In the second group of patients was observed in 14 patients euthyreose, from 2 - hypothyroidism, compensated reception L-thyroxine.

Results: Both groups of patients differed on the following parameters studied: erosion detected in $68 \%$ in group 1 and $50 \%$ in group $2(\mathrm{p}<0,05)$, in the first group of patients predominated $(62 \%)$ the high degree of activity of RA by DAS-28, in while in group 2 - the average $(56 \%, p<0,05)$.

By using correlation analysis Spearman correlation relationships among the studied attracted attention significant $(R=0,62, p<0,05)$ relationship between erosions and detection in the blood of antibodies to ACCP in the second group of patients (a combination of RA and HT and identifying in blood ACCP and AMCV), which was repeatedly weakened and unreliable in group 1 (combination of RA and HT and only detect of ACCP) in the blood.

Conclusions: Second group patients (a combination of RA with HT and detection in blood ACCP and AMCV) are closer correlations with indicators of joint destruction than group 1 patients, that in the future may use as a prognostic marker of a more severe course of RA in combination with $\mathrm{HT}$.

Disclosure of Interest: None declared

DOI: 10.1136/annrheumdis-2017-eular.4172

\section{AB0299 ATLANTOAXIAL SUBLUXATION AS A PROBLEM IN PATIENTS WITH RHEUMATOID ARTHRITIS}

S. Misevska Percinkova ${ }^{1}$, A.A. Kuchi ${ }^{2}$. ${ }^{1}$ Dept. for Inflamatory Rheumatic Disease, University Rheumatology Clinic; ${ }^{2}$ Dept. for Internal Medicine, PHO City Health Centre Skopje 1, Skopje, Macedonia, The Former Yugoslav Republic Of

Background: Atlantoaxial subluxation (AAS) is important and potentially life threatening complication of Rheumatoid arthritis (RA). It is defined when the space between odontoid process from $\mathrm{C} 2$ and arch of the atlas exceeds more than $3 \mathrm{~mm}$. Instability in atlantoaxial joint may result with numerous neurological symptoms, compression of spinal cord and ultimately quadriparesis or quadriplegia.

Objectives: Aim of the study was to determine the frequency and the characteristics of atlantoaxial instability among our patients with RA and its dependence on the nature of the disease.

Methods: 92 outpatients from University Rheumatology Clinic in Skopje, with classical RA (ACR criteria 1988) were examined for the AAS. In all cases were analysed the duration of the disease, haematological and serological tests, disease activity (DAS 28), visual analogue scale (VAS) for the degree of articular pain and verbal rating scale (VRS).for cervical-occipital pain. All patients underwent native and functional $x$-ray, CT scan and MRI of cervical spine. A complete neurological examination was obtained, with SEP of the $n$. medianus et $n$. tibialis. Results: Atlantoaxial instability, with expressed cervical-occipital symptomatology, occurred in 54 from $92(58,69 \%)$ patients with RA. AAS appeared significantly more often in patients with longer duration of the disease $(p<0,0001)$, in cases with significant cervical-occipital pain (VRS $p<0,0001$ ), with stronger joint pains (VAS), with higher values of SR $(p=0,002), \operatorname{CRP}(p=0,023), \operatorname{RF}(p=0,000005)$, anti CCP $(p=0,00003)$, and DAS $28(p<0,0001)$. Anaemia and thrombocytosis $(p=0,0008)$ appeared significantly more in cases with AAS. Anterior AAS, (mostly combined with other types) was the most frequent type, presented in 41 participants $(75,92 \%)$. In one case posterior AAS was detected, what is very rare finding. Positive SEP was significantly higher in the group with AAS

Conclusions: AAS is serious extra-articular manifestation of RA. Cervical subluxation may be a general anesthetic risk and risk for a neck injury. Routine cervical radiographs with the head in flexed position should be recommended in need of general anaesthesia and in situations with risk for a neck injury.

Acknowledgements: Rheumatoid arthritis, atlantoaxial subluxation.

Disclosure of Interest: None declared

DOI: 10.1136/annrheumdis-2017-eular.5033

\section{AB0300 ASSOCIATION OF VITAMIN D STATUS WITH RHEUMATOID ARTHRITIS DISEASE ACTIVITY AND UV INDEX}

C. Lopes $^{1}$, J.L. Gomes ${ }^{1,2}$, T. Costa ${ }^{1}$, M. Mateus ${ }^{1}$, F. Pimentel-Santos ${ }^{1,2}$, J.C. Branco ${ }^{1,2} .{ }^{1}$ Rheumatology Department, Hospital de Egas Moniz / CHLO; ${ }^{2}$ CEDOC, NOVA Medical School / Faculdade de Ciências Médicas - NOVA University of Lisbon, Lisbon, Portugal

Background: Lower serum vitamin D levels have been shown to be associated with various autoimmune disorders, including Rheumatoid Arthritis (RA). Vitamin $\mathrm{D}$ deficiency is common in RA patients, despite profiting from a sunny country. Objectives: The aim of the study is to evaluate (1) - the association between vitamin $D$ serum levels and disease activity in patients with $R A ;(2)$ - seasonal distribution of vitamin D levels.

Methods: Patients fulfilling the 2010 EULAR/ACR Rheumatoid Arthritis Classification Criteria, which had serum vitamin D [25(OH)D3] levels measured between January 2013 and December of 2016 were included. Demographic data, disease activity scores, including DAS283v-CRP and DAS283v-ESR, vitamin D supplementation with cholecalciferol and other therapeutic approaches were recorded. Vitamin D insufficiency was considered between $25-75 \mathrm{nmol} / \mathrm{L}$ and deficiency if $<25 \mathrm{nmol} / \mathrm{L}$. According to the national agency for the study of sea and atmosphere, UV Index levels were grouped into low UV Index 3-6 (October to April) and high UV Index 9-10 (May to September). Correlation between variables was analyzed using Spearman's rho.

Results: A sample composed by 95 patients, 79 females (83.16\%), with an average age (SD) of 68.57 (11.92) years within 40-88 years range were included. Average disease duration was $13.46(11.41)$ years. The average age at diagnosis was 57.10 (14.25) years. The average vitamin D levels were 78.13 (60.98) $\mathrm{nmol} / \mathrm{L}$ in a range between $20-400 \mathrm{nmol} / \mathrm{L}$. Vitamin D levels were not significantly different in male $v s$. females patients. The prevalence of vitamin $D$ insufficiency and deficiency was $53.68 \%$ and $8.42 \%$ respectively, despite $57.89 \%$ of the patients taking supplementation (average 6141 (4800) UI/week). The univariable analysis showed that albeit vitamin $\mathrm{D}$ levels presented a negative poor correlation with DAS283v-CRP (rho $=-0.348$, p-value $<0.001)$ and DAS283v-ESR (rho $=-0.271$, $p$-value $<0.01$ ), there was a direct reduction in dispersion of the vitamin $D$ values for increasing values of DAS283v-CRP and ESR. It was observed that vitamin D levels increase with patient age and decrease with disease duration. Sazonality and supplementation didn't affect vitamin D levels in our population.

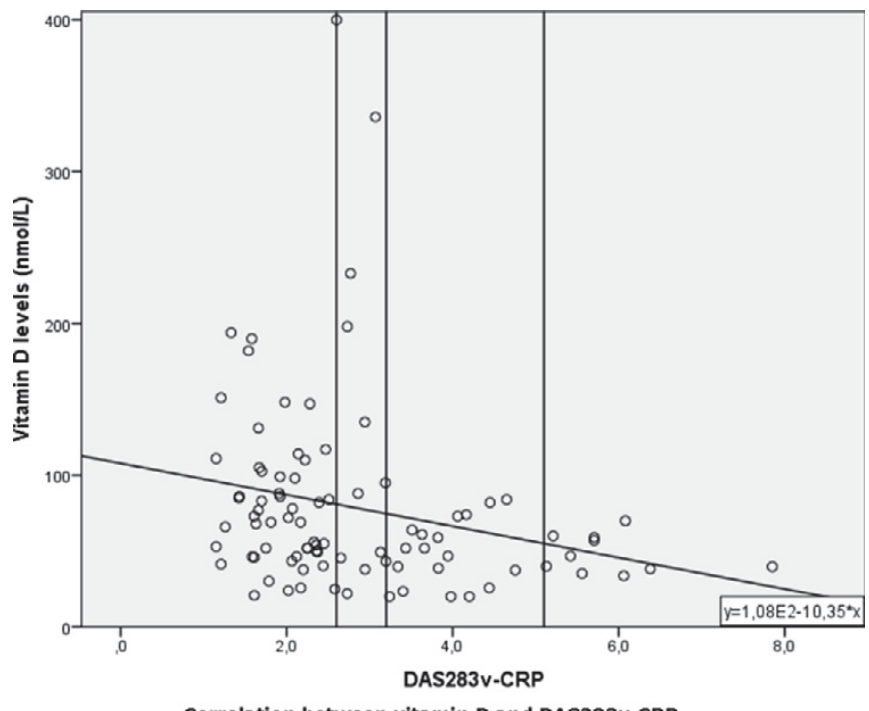

Conclusions: Vitamin D insufficiency/deficiency was frequent among RA patients $(62.1 \%)$, independently of seasonality or supplementation. An interesting pattern 